\title{
IMPORTANCIA DE LA ALFABETIZACIÓN EN SALUD PARA CONTENER LA TRANSMISIÓN DE LA PANDEMIA PROVOCADA POR EL VIRUS SARS-COV-2
}

\author{
IMPORTANCE OF HEALTH LITERACY IN CONTAINING PANDEMIC \\ TRANSMISSION DUE TO SARS-COV-2
}

\author{
Daniela Flores Durán \\ Marian Guzmán Trujillo \\ Jesús Domínguez Cruz \\ Alfredo Briones Aranda \\ alfred725@hotmail.com
}

Facultad de Medicina Humana. Universidad Autónoma de

CHIAPAS, MÉXICO 
Para citar este artículo:

Flores Durán, D., Guzmán Trujillo, M., Domínguez Cruz, J., \& Briones Aranda, A. (2020). Importancia de la alfabetización en salud para contener la transmisión de la pandemia provocada por el virus SARS-COV-2. ESPACIO I+D, INNOVACIÓN MÁS DESARROLLO, 9(25). https://doi.org/10.31644/IMASD.25.2020.a09

\section{RESUMEN}

El surgimiento exponencial de la pandemia por el virus SARS-COV-2 en México, es un tema de suma importancia que ha conllevado a la contención de su propagación, empleando diversas disciplinas médicas. Sin embargo, estrategias como la alfabetización en salud, que han sido ampliamente probadas y que son de bajo costo, requieren ser revisadas para mejorar su implementación. Por lo anterior, el propósito principal del presente manuscrito es analizar la importancia de la alfabetización en salud en la contención de la pandemia en México, con un estudio conceptual de los principales factores que participan en el desarrollo de esta enfermedad, como: el tipo de virus, los mecanismos fisiopatológicos, la interacción de factores sociodemográficos y culturales que forman parte del escenario epidemiológico. Las principales premisas integradas que han llevado a reconocer la necesidad de verificar la fuente de información, referente a los conocimientos médicos que continuamente se están difundiendo sobre la pandemia, para evitar la propagación de información falsa. Así como la importancia de aplicar las acciones preventivas sobre el uso del cubre bocas y el correcto lavado de manos, no a base de medidas obligatorias por sanciones, sino mediante la enseñanza razonada, que permita en las personas poder decidir mediante el auto consentimiento. No obstante, es necesario continuar con la enseñanza preventiva, involucrando diversos líderes poblacionales (políticos, religiosos, profesores, comunicólogos etc.) que puedan replicar con el ejemplo y facilitar la enseñanza de estas estrategias.

\section{Palabras clave}

Virus SARS-COV-2, alfabetización en salud, medidas preventivas, pandemia en México. 
The exponential rise of the SARS-COV-2 virus pandemic in Mexico is a major issue. We can contain its spread with the use of various medical disciplines. However, we need to review lowcost and tested strategies to improve their implementation, for one example health literacy. Thus, the main purpose of this work is to analyze the importance of health literacy in pandemic containment in Mexico. With a conceptual study, we identified the main factors that help develop this disease, those are the type of virus, the physiopathological mechanisms, the interaction between sociodemographic and cultural factors that are part of the epidemiological scenario. To avoid the spread of false medical information related to the pandemic, the need to verify the source is essential. It is also important to put in place preventive measures, like the use of masks and correct hand washing. But we must do this through reasoned teaching, not based on sanctioned mandatory measures. It is necessary to continue with preventive education, involving various population leaders (politicians, religious people, teachers, etc.), who can be an example and ease the teaching of these strategies.

\section{Keywords}

SARS-COV-2 virus, health literacy, preventive measures, pandemic in Mexico. 


\section{ASPECTOS GENERALES DE LOS FACTORES INVOLUCRADOS EN LA PANDEMIA POR EL VIRUS SARS- COV- 2}

L

os virus son agentes microscópicos inertes en el entorno extracelular, es decir estos elementos, fuera de las células, no tienen vida, por lo que son incapaces de reproducirse por sí mismos (Brooks, Carroll, \& Butel, 20l4). Estos agentes están formados en su interior por moléculas de ácidos nucleicos y en su parte exterior se pueden conformar por una capa de lípidos que los protegen del medio ambiente. Esta capa externa representa una cápsula o coraza que también está formada de proteínas, elementos indispensables que conforman los mecanismos con los que se adhiere a las células y que le permiten penetrar en los organismos vivos (Alarcón, 2013). Una vez dentro de las células, el ácido nucleico de los virus se puede combinar con el material genético del núcleo celular, en donde la maquinaria que la célula dispone para la síntesis de nuevas proteínas puede ser aprovechada para que se repliquen más virus y así, de manera exponencial, poder infectar otras células (Brooks, Carroll, \& Butel, 2014). Como ejemplo de este proceso, se podría recurrir a un pasaje histórico del legendario caballo de Troya, que en su interior escondía a guerreros fuertemente armados y que en la oscuridad de la noche descendieron por una puerta oculta del caballo y se apoderaron de la ciudad, en alusión a este ejemplo se ha designado a ciertos virus cibernéticos como troyanos.

Actualmente se han identificado diversos tipos de virus, que de acuerdo con sus características genéticas y el tipo de material que conforma su capa externa, se han clasificado en varias familias, tipos y subtipos. Los coronavirus son una familia de virus que miden entre 120 y 160 nanómetros (nm), un nanómetro es la milésima parte de una micra y una micra es la milésima parte de un milímetro, los virus son tan pequeños, que el ojo humano es incapaz de poder verlos a simple vista. Los virus se pueden observar mediante un microscopio electrónico; a diferencia de las bacterias, que sí se pueden observar con un microscopio óptico, esto es debido a que el tamaño de las bacterias es más grande que el de los virus, incluso estos últimos pueden infectar a una bacteria.

Los coronavirus presentan un genoma formado de ácido ribonucleico (RNA). Estos tipos de agentes infecciosos cuentan con una envoltura y en la superficie externa de ésta se encuentran proyecciones ampliamente espaciadas que tienen forma de palo de golf de $20 \mathrm{~nm}$ de longitud, las cuales, en conjunto, simulan la forma de una corona solar (de ahí el nombre) (Brooks, Carroll, \& Butel, 20l4).

Comúnmente, la extensa familia de los coronavirus pueden estar presente en diversos animales y escasas veces estos virus pueden trasmitirse hacia los humanos. De los siete tipos de coronavirus que pueden causar enfermedades en humanos, cuatro tipos se han relacionado con enfermedades 
de las vías respiratorias superiores. Sin embargo, tres nuevos tipos de coronavirus han surgido de reservorios animales durante los últimos 20 años y no solo causan enfermedades de las vías respiratorias, sino también pueden alterar la fisiología de diversos aparatos y sistemas del cuerpo humano, causando complicaciones graves y la muerte (NIAID, 2020).

El primero de ellos surgió en noviembre del año 2002, el coronavirus SARS (SARS-CoV) causante del síndrome respiratorio agudo severo, el cual ha desaparecido, ya que desde el 2004 no se han reportado más casos (NIAID, 2020). El síndrome respiratorio de Oriente Medio es causado por el coronavirus denominado MERS-CoV, identificado por primera vez en Arabia Saudita en septiembre del año 2012 (OMS, 2020). Recientemente, el tercer tipo de coronavirus fue nombrado por el Comité Internacional de Taxonomía de Virus (ICTV) como virus SARS-CoV-2 (Cascella, Rajnik, Cuomo, Dulebohn, \& Di Napoli, 2020). Éste es el causante de la enfermedad COVID-I 9 (WHO, 2020), surgió en China, en diciembre de 2019 y debido a su gran capacidad de contagio este virus fue declarado por la Organización Mundial de la Salud (OMS), como agente etiológico de la pandemia mundial, el II de marzo de 2020 (WHO, 2020).

El primer caso confirmado de COVID- 19 en México se diagnosticó el 27 de febrero del 2020 (SSA, 2020), pocos días antes de que se declarara la pandemia mundial. Un día después, el 28 de febrero, se confirmaron dos casos más (SSA, 2020). La fase I de la pandemia comenzó este día en México, y se caracterizó por casos de infección que únicamente fueron importados del extranjero, es decir, personas que contrajeron el virus fuera del país. Posteriormente, por el incremento exponencial del número de casos confirmados, se llegó a la Fase 3, el día 2 I de abril del 2020 (SSA, 2020) con más de 9,500 casos y más de 800 defunciones como consecuencia de esta pandemia (SSA, 2020).

Entonces ¿cómo un virus pudo generar su propagación tan rápidamente y de manera tan generalizada en la población? Se han registrado reportes que informan sobre la transmisión del virus SARS-COV-2 de una persona a otra, por contacto directo con un individuo infectado a través de gotitas respiratorias que se expulsan al hablar, toser y estornudar (Chan, Yuan, \& Kok, 2020), también llamadas “microgotas de Flügge” (Murillo- Godinez, 2009).

Las gotículas respiratorias pueden medir entre 5 al 0 micras $(\mu \mathrm{m})$ (González, González, \& Flores, 2008), las cuales pueden expandirse en forma de aerosoles (Alvarez-Nodarse, Esteban, \& Rodriguez Quintero, 2020).

Por lo tanto, los agentes virales pueden desplazarse desde menos de I metro (WHO, 2020) hasta distancias superiores (Alvarez-Nodarse, Esteban, \& Rodriguez Quintero, 2020), pudiendo permanecer de minutos a horas en el aire en suspensión, especialmente en espacios cerrados, lo que incrementa la probabilidad de contagio entre las personas (Navarro-Beltrán, 1984; WHO, 2020). Éstos gérmenes entran en contacto con la conjuntiva de 
los ojos o las mucosas de boca y nariz (WHO, 2020) e ingresan por la vía aérea hasta llegar a los sacos alveolares en nuestros pulmones (González, González, \& Flores, 2008). También se ha detectado que el virus puede permanecer por horas en diversas superficies como mesas, sillas, estantes, etc. En donde, a través del contacto accidental por las manos de las personas, estos gérmenes pueden ser llevados hacia la nariz o boca y debido a la falta de un correcto lavado de manos o desinfección, los virus podrían ingresar al organismo (Ong, Tan, Chia, Lee, \& Wong, 2020).

Con este método de propagación, cualquier persona podría ser susceptible (hasta cierto punto) de una posible infección, pero hay individuos o grupos de personas con características en común que incrementan su riesgo de contagio, posibilidad de presentar síntomas graves, mayor tiempo de recuperación y consecuentemente se incrementa el riesgo de mortalidad. En un estudio realizado en México, se informó que "respecto a las características demográficas de los contagios, hubo un claro predominio en personas con un rango de entre 30 y 59 años de edad y mayor frecuencia en hombres $(68,85 \%)$. Entre los fallecidos, las enfermedades de base más predominantes fueron hipertensión arterial, diabetes y obesidad”. (Suárez, Suarez Quezada, Oros Ruiz, \& \& Ronquillo De Jesús, 2020).

Para entender un poco más acerca de cómo éste virus entra y ataca a nuestro cuerpo, especialmente en pacientes con enfermedades crónicas, tenemos que saber cómo se efectúa su ingreso en las células. Primero, ocurre un fenómeno como de llave cerradura, el virus se une a un receptor de la superficie celular de un huésped (humano), en el caso del SARS-CoV-2, esta unión se da entre la proteína (S) del virus, esto sería como una llave y el receptor de la enzima convertidora de la angiotensina 2 (ACE2), que haría el papel de una cerradura (Hoffmann, y otros, 2020). Una vez completado el ingreso, se permite la salida del RNA genómico viral para su reproducción dentro de la célula huésped (Pastrian-Soto, 2020). Posteriormente, el RNA viral se replica y se producen proteínas víricas que serán ensambladas para producir nuevos virus, que infectarán otras células del organismo (Yan-Rong, y otros, 2020).

El receptor de ACE2 se halla expresado en el tracto respiratorio bajo (pulmón), corazón, riñón, estómago, vejiga, esófago e intestino y células epiteliales de la lengua (Yan-Rong, et al, 2020; Yuefei, et al, 2020). El receptor ACE2 contribuye en la regulación de la presión arterial. En consideración a lo anterior, este virus puede ocasionar una enfermedad generalizada, que en combinación con otras comorbilidades como: enfermedades cardiovasculares, endocrinas, inmunodepresoras, etc. (Mousavizadeh \& Ghasemi, 2020), pueden llegar a provocar una falla orgánica múltiple (Chen, 2020).

Por el contrario, existen también personas que presentan la infección, pero no desarrollan síntomas (asintomáticas infectantes), que actúan como trasmisores de la infección no identificados, convirtiendo al virus SARSCoV-2 en el agente viral más transmisible en el mundo (Suárez, 2020). 
Consecuentemente, es importante el poder enfrentar esta pandemia de forma responsable y segura, para impedir que el número de personas contagiadas aumente constantemente y así, contribuir a la adecuada funcionalidad de los sistemas de salud.

En los últimos meses, el personal de salud ha sido testigo de cómo esta nueva enfermedad puede hacer colapsar a los sistemas de salud de todo el mundo, y a pesar de tomar todas las medidas necesarias de precaución, el personal sanitario de las diferentes instituciones se encuentran en alto riesgo de contagio de forma continua, ya que son quienes tratan de forma directa con pacientes infectados e incluso entre sus mismos compañeros o colaboradores que cursan con esta enfermedad de forma asintomática.

En el ámbito sanitario, encargado de atender a los pacientes con la enfermedad por coronavirus, podemos encontrar diversas situaciones que comprometen la vida del mismo personal, ya que se encuentran en peligro inminente de contagio, además de estar realizando horas extras de trabajo por la falta de especialistas en el tema, así como el miedo o temor constante que llega a presentar el personal sanitario con respecto al riesgo de poder infectar a sus seres queridos.

¿Cómo podría afectar la pandemia el rendimiento del personal sanitario?

La presión social sobre los médicos también ha ido en ascenso, no siempre de manera positiva. Desde que la pandemia comenzó, la carga laboral para ellos aumentó, no tardaron en llegar los anuncios y slogans publicitarios poniéndolos como héroes al enfrentarse a esta situación, usando su vocación y esfuerzo, (Pintle, 2020) sumándole la gran cantidad de pacientes por atender, el uso del incómodo equipo de protección, así como pasar horas sin poder descansar o comer, frustrándolos a mayor nivel, y como consecuencia cayendo en depresión, distrés y ansiedad (Huremović, 2019). Estudios transversales recientes en China indican que los trabajadores en servicios de salud afectados por la COVID-19 presentan altas tasas de síntomas depresivos (50,4\%), ansiedad (44,6\%), insomnio (34\%), y distrés (72\%), mientras que el mismo estudio en población general mostró síntomas de depresión (16,5\%) y de ansiedad (28,8\%) (Wang, y otros, 2020).

\section{IMPORTANCIA DE LA ALFABETIZACIÓN EN SALUD ANTE LA PANDEMIA POR EL VIRUS SARS-COV-2 EN MÉXICO}

Es imprescindible tomar en consideración diversos factores que se conjugan en el escenario donde trascurre la pandemia como: el predominio de una población que únicamente cursó un nivel básico de educación. El repentino surgimiento de esta nueva enfermedad, en donde el agente etiológico es un viru,s que la población no puede ver a simple vista, no puede oler ni tocar. 
Así mismo, la facilidad para difundir información errónea de manera masiva, ha llevado consigo a un inadecuado conocimiento con respecto al tema, provocando confusión en la sociedad. Por mencionar algunos ejemplos de estos errores podemos hablar de los múltiples productos químicos que pueden "matar" al virus, partiendo que este agente infeccioso no tiene vida, entonces ¿cómo puede matarse? Los virus se eliminan, no se matan. Otro ejemplo son los remedios naturales o procedimientos milagrosos que se difunden con facilidad en las redes sociales y que aluden a tener la fórmula mágica o efectiva para prevenir la infección viral, tratar los síntomas de la enfermedad, sin tomar en consideración una previa investigación científica.

Mensajes confusos que incitan a las personas a no permitir la fumigación de los mosquitos en regiones tropicales del país, mencionando equivocadamente que los productos químicos utilizados en la fumigación contienen el virus que trasmite la enfermedad. $O$ la implementación de multas o sanciones administrativas en algunos lugares de México por la falta de uso de cubre bocas.

Para cambiar esta situación, la herramienta más adecuada en este caso es la alfabetización en salud, estrategia que puede modificar el comportamiento de la población con respecto a la salud, valiéndose de mediadores como el conocimiento de la enfermedad y la autoeficacia (Cudjoe, Delva, Cajita, \& Han, 2020). Pero ¿qué quiere decir alfabetización en salud?

La alfabetización en salud es un proceso que se basa en la enseñanza para la adquisición de habilidades en las personas que le permitan la búsqueda de información y obtención de conocimientos, para tomar decisiones y cambiar la conciencia mediante el razonamiento de lo que implica mantener una buena salud, todo esto determinado también por un cierto nivel de motivación y considerando el entorno sociocultural en donde viven las personas (Lazcano-Ponce \& Alpuche-Aranda, 2020). "Su definición incluye la perspectiva de salud pública, así como la perspectiva individual” (Sørensen, 20I2). Su concepto implica un enfoque de educación y comunicación para la salud más participativo y más empoderado hacia los individuos (Wang, 2000). Esta visión actual nos manda a abordar la implementación de las medidas preventivas para la contención de la pandemia de una manera multidisciplinaria (Montesi, 2017).

La alfabetización en salud considera inicialmente, el nivel educativo de las personas (Manganello, 2008). Porque la complejidad en la enseñanza y comprensión de los conceptos básicos de la enfermedad se tienen que particularizar, ya que no es lo mismo enseñar a una persona que únicamente cursó la primaria, que a otra que cursó el nivel medio superior. No obstante, la enseñanza debe de estar basada en la regla de oro de la sencillez, además de facilitar la adquisición de nuevos conocimientos, recalcando la correcta selección de fuentes de información, con la finalidad de revisar si esta información es de una fuente confiable, aludiendo a consejería de primero 
revisar quien es el autor que produce la información, verificar la fecha de publicación, y comparar con otras fuentes. Lo anterior podría evitar compartir cadenas de texto, audio o video e imágenes que provengan de fuentes desconocidas.

Para la implementación de esta estrategia educativa en salud, es indispensable recurrir a la capacitación inicial de los diversos líderes sociales de diferentes niveles, incluyendo el área de la política, el ámbito religioso, sindical, etc. Partiendo de que el entendimiento de estos líderes fomentará el buen ejemplo y ayudará en la explicación adecuada del porqué de la implementación y seguimiento de las medidas preventivas para contener la pandemia. También se debe implementar en los medios de comunicación masivos la trasmisión de mesas de análisis interactivas sobre la pandemia, entre especialistas en el tema y público en general.

La alfabetización en Salud ha sido asociada con beneficios importantes para los individuos y sus comunidades, en cuanto a los comportamientos y sus servicios (menores tasas de hospitalización o un uso más reducido de los servicios sanitarios y de urgencias) (ODPHP, 20I5). Por lo tanto, también tendrá un impacto en los resultados y en los costos de salud en la sociedad. A nivel comunitario, la alfabetización en salud incrementa la participación de las personas en los programas de salud poblacional; incrementando la capacidad de influir sobre las normas sociales (Nutbeam, 2000).

Una buena estrategia, en el caso de la pandemia por la COVID-19, es mejorar el conocimiento de los riesgos sobre el contagio, estrategia que podría contribuir en el cumplimiento de las acciones sanitarias prescritas por parte de los ciudadanos de manera individual y colectiva.

Sin duda alguna, el tema de la pandemia ha generado muchas dudas en los ciudadanos, pues se trata de algo nuevo para todos y, el miedo a lo desconocido, aunado a la falta de información, nos ha llevado a una búsqueda de soluciones de manera incorrecta.

Es importante recalcar que para poder salir de la situación actual lo más pronto posible y de la mejor manera (es decir, disminuir la tasa de contagios) debemos considerar cuidar la salud individual y colectiva. Es evidente que la COVID-I9 es una infección que tiene un alto grado de propagación, y no podemos cambiar la patogenicidad de este virus, así como el tiempo para generar una nueva vacuna, pero sí podemos trabajar todos juntos como sociedad, modificando nuestra rutina diaria con acciones simples pero significativas. 


\section{REFERENCIAS}

Alarcón, D. S. (05 de Junio de 2013). Instituto de Ecología. Recuperado el 07 de Septiembre de 2020, de Instituto de Ecología: https://www.inecol. $\mathrm{mx} /$ inecol/index.php/es/2013-06-05-10-34-10/17-ciencia-hoy/436-queson-los-virus-y-como-funcionan

Alvarez-Nodarse, R., Esteban, F. J., \& Rodriguez Quintero, N. (28 de Abril de 2020). ¿Hasta donde llega un virus al estornudar? Obtenido de Blog del Instituto de Matemáticas de la Universidad de Sevilla: https://institucional.us.es/blogimus/2020/04/hasta-donde-llega-un-virus-al-estornudar/

Brooks, F., Carroll, K., \& Butel, J. (2014). Jawetz, Melnick y Adelberg: Microbiologia Médica (26 ed.). McGraw-Hill Interamericana. Obtenido de https://accessmedicina. mhmedical. com/content. aspx?bookid=1507 \&sectionid $=102894197$

Cascella, M., Rajnik, M., Cuomo, A., Dulebohn, S., \& Di Napoli, R. (10 de August de 2020). Features, Evaluation, and Treatment of Coronavirus (COVID-19). StatPearls. Treasure Island (FL): StatPearls Publishing. Obtenido de StatPearls Publishing: https://www.ncbi.nlm.nih.gov/ books/NBK554776/

Chan, J., Yuan, S., \& Kok, K. (2020). A familial cluster of pneumonia associated with the 2019 novel coronavirus indicating person-to-person transmission: a study of a family cluster. Lancet. doi: 10.1016/ So140-6736(20)30154-9

Chen, N. Z. (2020). Características epidemiológicas y clínicas de 99 casos de neumonía por el nuevo coronavirus de 2019 en Wuhan, China: un estudio descriptivo. Lancet, 395(10223), 507-513. doi: 10.1016 / So140$6736(20) 30211-7$

Cudjoe, J., Delva, S., Cajita, M., \& Han, H.-R. (2020). Empirically Tested Health Literacy Frameworks. HLRP: Health Literacy Research and Practice, 4(1), 22-44. doi:10.3928/24748307-20191025-01

González, J., González, C., \& Flores, R. (2008). Tuberculosis pulmonar. En J. González, \& N. Suárez, Diagnóstico y tratamiento en neumología. (pág. 221). Mexico: El Manual Moderno.

Hoffmann, M., Kleine-Weber, H., Schroeder, S., Krüger, N., Herrler, T., \& Erichsen, S. (16 de Abril de 2020). SARS-CoV-2 Cell Entry Depends on ACE2 and TMPRSS2 and Is Blocked by a Clinically Proven Protease Inhibitor. Cell, 181(2), 271-280. doi:https://doi.org/10.1016/j. cell.2020.02.052

Huremović, D. (2019). Psychiatry of Pandemics. A Mental Health Response to Infection Outbreak ( 1 ed.). Springer International Publishing. doi:10.1007/978-3-030-15346-5 
Lazcano-Ponce, E., \& Alpuche-Aranda, C. (2020). Alfabetización en salud pública ante la emergencia de la pandemia por Covid-19. Salud Publica de Mexico. doi:10.21149/11408

Manganello, J. (2008). Alfabetización en salud y adolescentes: un marco y una agenda para futuras investigaciones. Salud Educ Res., 23(5), 840-847.

Montesi, M. (2017). Alfabetización en salud: revisión narrativa e interdisciplinar de la literatura publicada en biomedicina y en biblioteconomía y documentación. Revista Cubana de Información en Ciencias de la Salud, 28(3). Recuperado el 20 de Agosto de 2020, de http://scielo.sld. cu/scielo.php?script=sci_arttext\&pid=S2307-21132017000300007\&ln $\mathrm{g}=\mathrm{es} \& \mathrm{t}$ lng=es.

Mousavizadeh, L., \& Ghasemi, S. (March de 2020). Genotype and phenotype of COVID-19: Their roles in pathogenesis. Journal of Microbiology, Immunology and Infection. doi:10.1016/j.jmii.2020.03.022

Murillo- Godinez, G. (2009). Las gotitas de Flügge. Revista Medica del Instituto Mexicano del Seguro Social, 47(3), 290. Obtenido de https:// www.medigraphic.com/pdfs/imss/im-2009/imo93j.pdf

Navarro-Beltrán, I. (1984). Diccionario terminológico de ciencias médicas (12 ed.). Barcelona, España: Salvat Editores.

NIAID. (19 de Mayo de 2020). Coronaviruses. National Institute of Allergy and Infectious Diseases. NIH. Recuperado el 19 de Agosto de 2020, de https://www.niaid.nih.gov/diseases-conditions/coronaviruses

NIAID. (18 de Agosto de 2020). Covid-19, MERS y SARS. National Institute of Allergy and Infectious Diseases. NIH. Recuperado el 19 de Agosto de 2020, de National Institute of Allergy and Infectious Diseases: https:// www.niaid.nih.gov/diseases-conditions/covid-19

Nutbeam, D. (3 de Septiembre de 2000). Alfabetización en salud como objetivo de salud pública: un desafío para las estrategias de comunicación y educación para la salud contemporáneas en el siglo XXI. Health Promotion International, 15(3), 259-267. doi:10.1093/heapro/15.3.259

ODPHP. (2015). Health Literacy Online: A guide to simplifying the user experience. Office of Disease Prevention and Health Promotion. U S. Services, Ed. Obtenido de https://health.gov/healthliteracyonline/

OMS. (2014). Prevención y control de las infecciones respiratorias agudas con tendencia epidémica y pandémica durante la atención sanitaria. Ginebra: Organización Mundial de la Salud. Obtenido de https://www. paho.org/hq/dmdocuments/2014/2014-cha-prevencion-control-atencionsanitaria.pdf

OMS. (Enero de 2020). Coronavirus causante del Síndrome respiratorio de Oriente Medio (MERS-CoV). Organizacion Mundial de la Salud. Recuperado el 17 de Agosto de 2020, de World Health Organization: https://www.who.int/features/qa/mers-cov/es/ 
Ong, S., Tan, Y., Chia, P., Lee, T., \& Wong, M. (4 de Marzo de 2020). Air, surface environmental, and personal protective equipment contamination by severe acute respiratory syndrome coronavirus 2 (SARS-CoV-2) from a symptomatic patient. JAMA, 323(16), 1610-1612. doi:10.1001/ jama.2020.3227

Pastrian- Soto, G. (2020). Bases Genéticas y Moleculares del COVID-19 (SARS-CoV-2). Mecanismos de Patogénesis y de Respuesta Inmune. International journal of odontostomatology, 14(3), 331-337. doi:10.4067/ So718-381X2020000300331

Pintle, F. (27 de Mayo de 2020). Personal médico sufre estrés y ansiedad en medio de la pandemia. Business Insider México / Noticias pensadas para ti. Obtenido de https://businessinsider.mx/ estres-ansiedad-personal-medico-coronavirus-salud-mental/

Sørensen, K. V. (2012). Alfabetización en salud y salud pública: una revisión sistemática e integración de definiciones y modelos. BMC Public Health, 12(80). doi:10.1186/1471-2458-12-80

SSA. (21 de Abril de 2020). Comunicado Tecnico Diario COVID-19. Secretaria de Salud. Obtenido de Secretaia de Salud: https://www.gob.mx/cms/ uploads/attachment/file/571057/Comunicado_Tecnico_Diario_COVID19_2020.04.21.pdf

SSA. (28 de Febrero de 2020). Comunicado Técnico Diario COVID-19. Secretaria de Salud. Obtenido de Secretaria de Salud: https://www. gob.mx/cms/uploads/attachment/file/571278/Comunicado_Tecnico_ Diario_COVID-19_2020.02.28.pdf

SSA. (2020). Comunicado Técnico Diario Nuevo Coronavirus en el Mundo (COVID-19). Secretaría de Salud. Obtenido de https://www.gob.mx/salud/ documentos/coronavirus-covid-19-comunicado-tecnico-diario-238449

SSA. (21 de Abril de 2020). Secretaria de Salud. Inicia la fase 3 por COVID-19 [Conferencia de Prensa]. Obtenido de Secretaria de Salud: https://www. gob.mx/salud/prensa/110-inicia-la-fase-3-por-covid-19

Suárez, V., Suarez Quezada, M., Oros Ruiz, S., \& \& Ronquillo De Jesús, E. (27 de Mayo de 2020). Epidemiología de COVID-19 en México: del 27 de febrero al 30 de abril de 2020. Revista Clínica Española (English Edition). doi:10.1016/j. rce.2020.05.007

Wang, C., Pan, R., Wan, X., Tan, Y., Xu, L., Ho, C. S., \& \& Ho, R. C. (06 de March de 2020). Immediate Psychological Responses and Associated Factors during the Initial Stage of the 2019 Coronavirus Disease (COVID-19) Epidemic among the General Population in China. Int $J$ Environ Res Public Health, 17(5), 1729. doi:10.3390/ijerph17051729

Wang, R. (2000). Alfabetización en salud crítica: un estudio de caso de China en el control de la esquistosomiasis. Health Promotion International, 15(3), 269-274. doi:10.1093/heapro/15.3.269 
WHO. (29 de Marzo de 2020). Modes of transmission of virus causing COVID-19:implications for IPC precaution recommendations. World Health Organization. Obtenido de World Health Organization (WHO): https://www.who.int/es/news-room/commentaries/detail/modes-oftransmission-of-virus-causing-covid-19-implications-for-ipc-precautionrecommendations

WHO. (11 de Febrero de 2020). Novel Coronavirus (2019-nCoV) Situation Reports. World Health Organization. Obtenido de World Health Organization (WHO): https://www.who.int/docs/default-source/coronaviruse/situationreports/20200211-sitrep-22-ncov.pdf

WHO. (11 de Marzo de 2020). Palabras de apertura del Director General de la OMS en la rueda de prensa sobre el COVID-19 - [Comunicado de prensa]. Obtenido de World Health Organization. (WHO): World Health Organization. (WHO) Direct https://www.who.int/dg/speeches/detail/ who-director-general-s-opening-remarks-at-the-media-briefing-on-covid19---11-march-2020

Yan-Rong, G., Qing-Dong, C., Zhong-Si, H., Yuan-Yang, T., ShouDeng, C., Hong-Jun, J., . . . De-Yun, W. \&. (2020). The origin, transmission and clinical therapies on coronavirus disease 2019 (COVID 19) outbreak - an update on the status. Military Med Res , 7(11). doi:10.1186/s40779-020-00240-0

Yuefei, J., Haiyan, Y., Wangquan, J., Weidong, W., Shuaiyin, C., \& Weiguo, Z. \&. (2020). Virology, Epidemiology, Pathogenesis, and Control of COVID19. Viruses, 12(4), 372. doi:10.3390/v12040372 